\title{
The Effect of Clonidine Therapy on Height and Growth Velocity in Constitutional Growth and Puberty Delay
}

\author{
Zahra Razavi, ${ }^{1}$ Fahimeh Rabbani, ${ }^{1}$ and Hassan Bazmamoun ${ }^{1,}$ \\ ${ }^{1}$ Department of Pediatrics, Hamedan University of Medical Sciences, Hamedan, IR Iran \\ "Corresponding author: Hassan Bazmamoun, Department of Pediatrics, Hamedan University of Medical Sciences, Hamedan, IR Iran. E-mail: hbazmamoun@yahoo.com
}

Received 2015 April 25; Accepted 2015 November 16.

\begin{abstract}
Background: Constitutional delay of growth and puberty(CDGP) is the most common cause of short stature. This variant of normal growth can be associated with psychological stress in some affected individuals.

Objectives: We aimed to assess the effects of clonidine on short-term growth rate in children and adolescents with constitutional growth delay.

Patients and Methods: In this prospective, randomized clinical trial study, 48 prepubertal constitutionally short boys (6 -12 years old) with height standard deviation scores (HSDS) less than -2, bone age delay $2.1 \pm 0.2$ years, GH concentration $>10 \mu \mathrm{g} / \mathrm{L}$ after provocation and growth rates $<5 \mathrm{~cm} /$ year were included. Subjects were randomly assigned to group A $(\mathrm{n}=24)$ who received clonidine 0.1 $\mathrm{mg} / \mathrm{m} 2$ or group $B(n=24)$ who received placebo before sleep for 6 months. Height, weight and growth velocity were measured in 6th and 12 th months.

Results: Mean age and height in two groups were similar at baseline. Mean growth velocity in group A was $2.9 \pm 0.91$ and $3.1 \pm 0.98$ $\mathrm{cm} / 6$ month at baseline and 6th months, respectively and in group B was $2.9 \pm 0.94$ and $2.4 \pm 0.47 \mathrm{~cm} / 6$ month at baseline and 6 th months, respectively $(\mathrm{P}=0.01)$. Mean HSDS in group A was $-2.79 \pm 0.65$ and $2.39 \pm 0.39$ at baseline and 6 th months, respectively and in group B was $2.69 \pm 0.73$ and $2.39 \pm 0.48$ at baseline and 6 th months, respectively.

Conclusions: Although a slightly increase in HSDS was observed in treated group, but difference was not significant compared with control subjects. So, clonidine therapy could not improve height standard deviation score and growth velocity of children and adolescents with CDGP.
\end{abstract}

Keywords: Clonidine, Short stature, Normal Variant Growth

\section{Background}

Constitutional growth delay and puberty(CGDP) refers to children and adolescents who are very short compared with their peers. CGDP is the most common cause of short stature and delayed puberty and is more prevalent in boys [1-3]. Approximately $15 \%-17.7 \%$ of patients with short stature referred for endocrinologic evaluation have constitutional growth delay $[4,5]$. Children with CGDP do not have any diseases and enter puberty later than their peers. They continue to grow and reach their adult height later, which is normal and comparable to their parents. Medical treatment of this variation of normal growth is not necessary and reassurance alone remains the main modality. However, CGDP can contribute to psychological difficulties and affect school performance and social relationships [2]. In addition, it has been suggested that delay in puberty might be a risk factor for adult osteopenia [6]. On this basis, clinicians may consider the treatment options in these children in order to improve their growth rate. In previous studies, it has been hypothesized that al- pha 2-adrenoceptor activation by clonidine has a stimulatory effect on growth hormone (GH) release [5, 7-9]. The use of clonidine in children with CGDP has been the subject of several studies $[8,9]$ but, very divergent results have been reported and therefore the effectiveness of clonidine in increasing growth rate of CGDP is not clear. Many subjects affected by constitutional short stature show a good response to human growth hormone (HGH) therapy, whereas others do not benefit by this treatment [10-13]. The use of aromatase inhibitors and oxandrolone, a weak anabolic steroid has been shown to be effective in children with CGDP. Results are encouraging in terms of effective increase in height $[14,15]$. The short courses of low-dose testosterone therapy also appear to be efficacious and safe for treatment of appropriately selected individual's boys with constitutional delay of growth and puberty $[16,17]$.

\section{Objectives}

The objective of this study was to investigate the effect of clonidine on growth velocity in prepuberal boys with 
CGD.

\section{Patients and Methods}

This prospective, randomized clinical trial was conducted at pediatric endocrine clinic of Besat hospital, Hamedan, Iran from September 2009 to September 2010. The study was approved in ethics and research committee of Hamedan University of Medical Sciences and written informed consent was obtained from all subjects or their parents.

\subsection{Inclusion Criteria}

The diagnosis of CGDP was defined as [10] height below the third percentile or $>2$ standard deviation (SD) below that of children of the same chronological age and sex, according to center for disease control (CDC) clinical growth charts based reference, delayed bone age (by $\geq 2$ years), low growth rates $<5 \mathrm{~cm} / \mathrm{y}$, GH response of $>10 \mu \mathrm{g} / \mathrm{L}$ to at least two stimulation tests (clonidine and exerciseinduced) in otherwise healthy prepubertal boys. Systemic or specific causes of short stature were ruled out by history, physical examination and routine laboratory tests.

\subsection{Exclusion criteria}

Subjects were excluded if they were taking any medication or developed acute or chronic illnesses that impaired growth or entered puberty at the study period or did not adhere to treatment and follow-up.

\subsection{Study Subjects}

Forty-eight prepubertal boys ( 6 - 12 years) with CGDP who met inclusion criteria were recruited. A detailed questionnaire of the required information was completed and pubertal Tanner staging and accurate height measurement (by Seca wall-mounted stadiometer) were made at baseline and every 3 months. Height Standard deviation score (HSDS) were assessed regularly.

Standard deviation score is defined by the formula: actual height minus mean height for age divided by standard deviation of height for age. In all recruited subjects screen blood tests were done and bone age was determined by examining a radiograph of the left hand and wrist. An expert examiner who was blinded as to which subjects are in trial or control groups took measures at baseline and followup. Subjects were randomly assigned to either clonidine (made by Tolid Daru company, Iran) treatment group or control group. Main outcome measure was growth rate 6 months before and 6 months after treatment with clonidine. Six months observation without any treatment followed by an immediately 6 months period during which nightly dose of clonidine $\left(0.1 \mathrm{mg} / \mathrm{m}^{2}\right.$ by mouth) was administered in all subjects treatment arm of the study. The results of 6 months of clonidine therapy were compared with who received placebo before sleep for 6 months. The subjects had a full examination every 3 months. They were instructedto report any drug side effects.

\subsection{Statistical Analysis}

The statistical analyses were performed using the standard statistical package SPSS-15. One-way ANOVA and Tukey tests were employed to evaluate differences between groups. Independent t-test and paired t-test were applied to compare the growth rate changes and difference within groups, respectively. Results are expressed as mean \pm SD. P $<0.01$ was considered statistically significant.

\section{Results}

During one year duration of study, 51 boys were included but 3 individual were excluded because they did not completed study. The mean chronological age was $10.92 \pm 1.79$ and $10.25 \pm 1.91$ years in treated and control groups, respectively. At baseline, the mean \pm SD of height in both groups did not have significant difference. A mean increase in HSDS was observed in treated group (Table 1). But was not statistically significant compared with control subjects. In treated group, height velocity (cm/6 months) increased but in control group height velocity decreased (Table 2). The mean growth rate velocity was $+1.45 \pm 1.29$ and $+0.9 \pm 0.5 \mathrm{~cm} / 6$ months in treated and control groups, respectively. Any serious adverse event was not occurred. Three subjects had mild drowsiness, orthostatic hypotension and knee joint pain which diminished with drug consumption.

Table 1. Height Standard Deviation Scores Changes of Studied Subjects

\begin{tabular}{lcc}
\hline Mean \pm SD Of Height & \multicolumn{2}{c}{ Groups } \\
\cline { 2 - 3 } & Clonidine Group & Control Group \\
\hline Before treatment & $-2.79 \pm 0.65$ & $-2.39 \pm 0.39$ \\
After treatment & $-2.69 \pm 0.73$ & $-2.39 \pm 0.48$ \\
P-Value & 0.35 & 0.29 \\
\hline
\end{tabular}

\section{Discussion}

In present study, we found that growth height velocity in subjects who receivedclonidine, slightly increased. However, difference was not significant compared with control group. Compliance in our subjects was very good 
Table 2. Growth Rate Before and 6 Months After Study

\begin{tabular}{lccc}
\hline Groups & Clonidine Group & Control Group & P Value \\
\hline $\begin{array}{l}\text { Growth rate before } \\
\text { treatment }(\mathbf{c m} / \mathbf{6} \\
\text { months) }\end{array}$ & $2.9 \pm 0.91$ & $2.9 \pm 0.94$ & 0.66 \\
$\begin{array}{l}\text { Growth rate after } \\
\text { treatment }(\mathbf{c m} / 6 \\
\text { months) }\end{array}$ & $3.1 \pm 0.98$ & $2.4 \pm 0.47$ & 0.012 \\
\hline
\end{tabular}

and no secondary reactions were observed. Our results are consistent with a number of previous reports that demonstrated clonidine is not capable of increasing growth rate in boys with CGDP $[18,19]$. Pescovitz and Tan found that clonidine does not have a beneficial effect on linear growth velocity of CGDP [18] and Allen showed that clonidine therapy at bed time for 6 months did not increase growth velocity or plasma insulin-like growth factor I levels compared to placebo [19]. In contrast with the current study, Loche et al. [20] evaluated the effect of clonidine therapy on 24 hours integrated GH secretion in eight children with constitutional growth delay (CGD). They indicated that clonidine is capable of increasing GH levels and accelerate growth in studied children. Similarly in study of Casanova Bellido et al. on 23 prepubertal children (11 boys and 12 girls) six months treatment with clonidine resulted in increased the growth speed and the somatomedin C levels and decreased the height SD score, in $87 \%$ of the subjects [21].

According to a study of Pintor et al. in 25 of 34 children, the height velocity considerably increased with clonidine therapy and in 21 of them by more than $2 \mathrm{~cm} / \mathrm{yr}$ during the first 6 months of treatment. They concluded that clonidine may be a useful form of therapy for children with CGDP [22]. Similarly in a prospective study by DorantesAlvarez et al. clonidine administration in children with familial or constitutional growth short stature, increased height velocity in both groups [23]. Moreno Esteban et al. and Calzolari et al. [24, 25] also claimed that clonidine was helpful in increasing growth velocity of patients with constitutional growth delay. Above disagreement and discrepancies of studies results, may be due to differences in baseline characteristic in studies populations, causes of short stature, different clonidine prescription and additional treatment with vitamins or calcium replacement in some studies. Compliance in our subjects was very good and no secondary reactions were observed. These results were also similar to those of others researchers [22, 23].

\subsection{Limitations}

The data of this study was not sufficiently powered to be extrapolated to the large clinical setting. Therefore, it warrants compaction with results of previously reported findings.

The result of this study indicates that clonidine therapy would not be expected to be a particularly effective strategy to promote linear growth. We can therefore not recommend this form of therapy for children with constitutional growth delay.

\section{Acknowledgments}

The results in this article are from the thesis of pediatric board of Dr Fahimeh Rabbani, grant number 14533916/35/9. The authors are grateful to all the participants in this study for their cooperation. We also thank Khosro Mani-Kashani a faculty member of the statistics department of Hamedan University of Medical Sciences for his valuable statistical consultancies, and Sina Ahmadi, medical student from Hamedan medical school, for his research assistance. This study was performed by permission of committee of ethics in Hamedan medical school of Hamedan University of Medical Sciences.

\section{Footnotes}

Authors' Contribution: Conception and design: Zahra Razavi, Fahimeh Rabbani, Hassan Bazmamoun. Analysis and interpretation: Zahra Razavi, Fahimeh Rabbani, Hassan Bazmamoun. Data collection: Zahra Razavi, Hassan Bazmamoun. Writing the article: Zahra Razavi, Hassan Bazmamoun. Critical revision of the article: Hassan Bazmamoun. Final approval of the article: Bazmamoun H. Statistical analysis: Zahra Razavi, Hassan Bazmamoun. Obtained funding: Zahra Razavi and Overall responsibility: Hassan Bazmamoun.

Conflict of Interest: Researchers declare no conflict of interest.

Funding/Support: Undersecretary of Hamedan University of Medical Sciences.

\section{References}

1. Sultan M, Afzal M, Qureshi SM, Aziz S, Lutfullah M, Khan SA, et al. Etiology of short stature in children. J Coll Physicians Surg Pak. 2008;18(8):493-7. [PubMed: 18798587].

2. De Luca F, Argente J, Cavallo L, Crowne E, Delemarre-Van de Waal HA, De Sanctis C, et al. Management of puberty in constitutional delay of growth and puberty.JPediatr Endocrinol Metab. 2001;14 Suppl 2:953-7. [PubMed: 11529401].

3. Garganta MD, Bremer AA. Clinical dilemmas in evaluating the short child. Pediatr Ann. 2014;43(8):321-7. doi: 10.3928/00904481-2014072311. [PubMed: 25102486].

4. Clark AP, Kemp S. Constitutional growth delay 2014. Available from: http://emedicine.medscape.com/article/919677-overview. 
5. Song KC, Jin SL, Kwon AR, Chae HW, Ahn JM, Kim DH, et al. Etiologies and characteristics of children with chief complaint of short stature. Ann Pediatr Endocrinol Metab. 2015;20(1):34-9. doi: 10.6065/apem.2015.20.1.34. [PubMed: 25883925].

6. Pozo J, Argente J. Ascertainment and treatment of delayed puberty. Horm Res. 2003;60 Suppl 3:35-48. [PubMed: 14671394].

7. van Vught AJ, Dagnelie PC, Arts IC, Froberg K, Andersen LB, ElNaaman B, et al. Dietary arginine and linear growth: the Copenhagen School Child Intervention Study. Br J Nutr. 2013;109(6):1031-9. doi: 10.1017/S0007114512002942. [PubMed: 23046689].

8. Zaccaria M. [Pharmacologic treatment of constitutional short stature]. Minerva Endocrinol. 1990;15(1):73-8. [PubMed: 2274017].

9. Ghigo E, Goffi S, Mazza E, Imperiale E, Arvat E, Bellone J, et al. Acute administration of pyridostigmine and clonidine has an additive stimulatory effect on GH release in normal children. J Endocrinol Invest. 1989;12(2):99-101. doi: 10.1007/BF03349930. [PubMed: 2754188].

10. Poyrazoglu S, Gunoz H, Darendeliler F, Saka N, Bundak R, Bas F. Constitutional delay of growth and puberty: from presentation to final height. J Pediatr Endocrinol Metab. 2005;18(2):171-9. [PubMed: 15751606].

11. Sedlmeyer IL, Palmert MR. Delayed puberty: analysis of a large case series from an academic center.J Clin Endocrinol Metab. 2002;87(4):161320. doi: 10.1210/jcem.87.4.8395. [PubMed: 11932291].

12. Wit JM, Reiter EO, Ross JL, Saenger PH, Savage MO, Rogol AD, et al. Idiopathic short stature: management and growth hormone treatment. Growth Horm IGF Res. 2008;18(2):111-35. doi: 10.1016/j.ghir.2007.11.003. [PubMed: 18178498].

13. Krajewska-Siuda E, Malecka-Tendera E, Krajewski-Siuda K. Are short boys with constitutional delay of growth and puberty candidates for rGH therapy according to FDA recommendations?. Horm Res. 2006;65(4):192-6. doi: 10.1159/000092120. [PubMed: 16549932].

14. Harrington J, Palmert MR. Clinical review: Distinguishing constitutional delay of growth and puberty from isolated hypogonadotropic hypogonadism: critical appraisal of available diagnostic tests. $J$ Clin Endocrinol Metab. 2012;97(9):3056-67. doi: 10.1210/jc.2012-1598. [PubMed: 22723321].

15. Krebs A, Moske-Eick O, Doerfer J, Roemer-Pergher C, van der Werf-
Grohmann N, Schwab KO. Marked increase of final height by longterm aromatase inhibition in a boy with idiopathic short stature. $J$ Pediatr Endocrinol Metab. 2012;25(5-6):581-5. [PubMed: 22876562].

16. Soliman AT, De Sanctis V. An approach to constitutional delay of growth and puberty. Indian J Endocrinol Metab. 2012;16(5):698-705. doi: 10.4103/2230-8210.100650. [PubMed: 23087852].

17. Ambler GR. Androgen therapy for delayed male puberty. Curr Opin Endocrinol Diabetes Obes. 2009;16(3):232-9. [PubMed: 19396985].

18. Pescovitz $\mathrm{OH}$, Tan E. Lack of benefit of clonidine treatment for short stature in a double-blind, placebo-controlled trial. Lancet. 1988;2(8616):874-7. [PubMed: 2902319].

19. Allen DB. Effects of nightly clonidine administration on growth velocity in short children without growth hormone deficiency: a doubleblind, placebo-controlled study. J Pediatr. 1993;122(1):32-6. [PubMed: 8419612].

20. Loche S, Puggioni R, Fanni T, Cella SG, Muller EE, Pintor C. Aug mentation of growth hormone secretion in children with constitutional growth delay by short term clonidine administration: a pulse amplitude-modulated phenomenon. J Clin Endocrinol Metab. 1989;68(2):426-30. doi: 10.1210/jcem-68-2-426. [PubMed: 2918053].

21. Casanova Bellido M, Garcia Valderrama P, Rico de Cos S. [Evaluation of the treatment with clonidine of short stature in children]. An Esp Pediatr. 1989;31(3):233-9. [PubMed: 2631606].

22. Pintor C, Cella SG, Loche S, Puggioni R, Corda R, Locatelli V, et al. Clonidine treatment for short stature. Lancet. 1987;1(8544):1226-30. [PubMed: 2884368].

23. Dorantes-Alvarez L, Coyote-Estrada N, Parra-Paredes S, Garcia-Morales L, Metlich-Medlich B. [Effects of clonidine++ administration in children with familial short stature and retarded body growth]. Bol Med Hosp Infant Mex. 1992;49(7):422-6. [PubMed: 1418649].

24. Moreno Esteban B, Monereo Mejias S, Rodriguez Poyo-Guerrero P, Moreno Esteban FJ, Tresguerres JA. One year treatment with clonidine in children with constitutional growth delay.J Endocrinol Invest. 1991;14(2):75-9. doi: 10.1007/BF03350268. [PubMed: 2061572].

25. Calzolari G, Bellini M, Alboni S, Riva P, Bonati E. [Clonidine in the treatment of short stature: preliminary clinical experience]. G Clin Med. 1990;71(8-9):517-20. [PubMed: 2279627]. 